\title{
Effects of Oral Isotretinoin Therapy on Nasal Dryness and Nasal Obstruction in Patients with Acne Vulgaris: Objective and Subjective Assessments Based on the Dose and Duration of Therapy
}

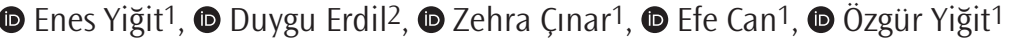 \\ 1 University of Health Sciences Turkey, İstanbul Training and Research Hospital, Clinic of Otorhinolaryngology, İstanbul, Turkey \\ 2University of Health Sciences Turkey, İstanbul Training and Research Hospital, Clinic of Dermatology, İstanbul, Turkey
}

\begin{abstract}
Introduction: This study aimed to evaluate the effect of oral isotretinoin therapy on nasal dryness and nasal obstruction in patients with acne vulgaris.

Methods: A total of 102 patients with acne vulgaris (mean \pm standard deviation age, $21.1 \pm 3.4$ years; female, $64.7 \%$ ) initiating systemic isotretinoin treatment [in $0.25 \mathrm{mg} / \mathrm{kg} /$ day $(n=35)$ or $0.5 \mathrm{mg} / \mathrm{kg} / \mathrm{day}(\mathrm{n}=67)$ doses] were enrolled in this prospective study. Data on nasal obstruction [via nasal obstruction symptom evaluation (NOSE)] and nasal dryness via a psychometric response scale [visual analog scale (VAS)] and nasal Schirmer test values (right and left Schirmer values) were recorded at baseline. Nasal dryness (VAS and nasal Schirmer test) and nasal obstruction (NOSE) assessments were repeated at months 2 and 4 of treatment in isotretinoin groups.

Results: The right Schirmer values at month $2(p<0.05)$ in the $0.25 \mathrm{mg}$ isotretinoin group and right $(p<0.01$ for each) and left $(p<0.001$ and $p<0.01$, respectively) Schirmer values at months 2 and 4 in the $0.5 \mathrm{mg}$ isotretinoin group significantly decreased from baseline, while VAS scores at months 2 and $4(p<0.001$ and $p<0.01$, respectively) significantly increased in the 0.5 mg isotretinoin group.

Conclusion: Our findings revealed the association of isotretinoin treatment with the occurrence of nasal dryness but not with nasal obstruction in patients with acne vulgaris, particularly with the high-dose daily regimen, regardless of treatment duration. The nasal Schirmer test is an objective assessment of nasal dryness in patients receiving isotretinoin therapy and the potential benefit of lowdose isotretinoin in reducing the risk of nasal dryness.
\end{abstract}

Keywords: Nasal dryness, nasal obstruction, isotretinoin dose, acne vulgaris, nasal Schirmer test

\section{Introduction}

Isotretinoin, used orally, is successfully used for acne treatment for more than two decades. It is a first-generation retinoid with pleiotropic effects on etiological factors involved in acne pathogenesis such as keratinocyte differentiation, proliferation, and sebaceous gland activity (1-3). However, the mechanism of action is considered to adversely affect mucociliary regrowth, refunctioning, and clearance properties of the nasal epithelium $(4,5)$.

Nasal secretion plays a vital role in humidification, heating, and cleaning of inspired air and participates in the first-line defense of the respiratory tract (6-9). Notably, the viscosity, elasticity, and adhesion properties of the mucus are important in mucociliary clearance and thus in the prevention of mucous stasis, secondary infection, and chronic dryness $(4,5,8)$.
Several studies have reported that isotretinoin was associated with negative effects on the nasal mucosa and mucociliary functions, including the induced epithelial and mucociliary differentiation, inhibition of squamous cell differentiation, and impaired mucociliary clearance time (MCT) (4,5,10-13). However, despite the consideration of reduction in mucosal secretion and dryness of the nasal surface mucosa in the etiology of the two common side effects of isotretinoin treatment including the prolonged MCT and the epistaxis (2,4,5,12-15), nasal dryness has not been extensively studied using objective measures in patients receiving isotretinoin.

Problems related to nasal secretion (sensation of a dry or runny nose) are among the most frequent patient-reported complaints in otolaryngology practice $(8,16)$. However, their diagnosis is mainly based on the subjective clinical description, as only a few objective tests are

Address for Correspondence: Enes Yiğit MD, University of Health Sciences Turkey, İstanbul Training and Research

Received: 01.11.2021 Hospital, Clinic of Otorhinolaryngology, İstanbul, Turkey Phone: +90 5544701180 E-mail: enesssyigit@hotmail.com ORCID ID: orcid.org/0000-0002-9853-6238

Cite this article as: Yiğit E, Erdil D, Çınar Z, Can E, Yiğit Ö. Effects of Oral Isotretinoin Therapy on Nasal Dryness and Nasal Obstruction in Patients with Acne Vulgaris: Objective and Subjective Assessments Based on the Dose and Duration of Therapy. İstanbul Med J 2022; 23(1): 1-5.

(C) Copyright 2022 by the University of Health Sciences Turkey, Istanbul Training and Research Hospital/istanbul Medical Journal published by Galenos Publishing House. 
available for measuring nasal humidity with limited use in routine clinical practice because of the need for special equipment or associated patient discomfort $(7,9,16-18)$.

As the nasal Schirmer test is an easily applicable, low-cost, and rapid tool in the objective assessment of nasal secretion and nasal mucosal moisture, it is considered promising in this regard $(7,9,16)$. Thus, the nasal Schirmer test, a modified version of the Schirmer test used in evaluating lacrimation in ophthalmology practice, is now increasingly used in otolaryngology practice in evaluating the amount of nasal secretion $(7,9,16)$.

This study aimed to investigate the effect of oral isotretinoin therapy on nasal dryness and nasal obstruction through objective (Schirmer values) and subjective [visual analog scale (VAS), nasal obstruction symptom evaluation (NOSE) scores] measures, with respect to the dose and duration of therapy in patients with acne vulgaris.

\section{Methods}

\section{Study Population}

A total of 102 dermatology outpatients [mean \pm standard deviation

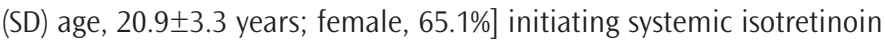
treatment [in $0.25 \mathrm{mg} / \mathrm{kg} /$ day $(\mathrm{n}=35)$ or $0.5 \mathrm{mg} / \mathrm{kg} /$ day $\quad(\mathrm{n}=67)$ doses] for acne vulgaris were enrolled in this prospective 4-month isotretinoin follow-up study. The study was conducted at a tertiary care otolaryngology clinic. Patients with a history of nasal surgery, upper respiratory tract infection within the last 4 weeks, active or ex-smokers, and took topical or systemic medication (i.e., steroids), and had rhinitis, chronic sinusitis, nasal polyp, septum deviation, chronic otitis media, concha hypertrophy, or any systemic disease were excluded from the study.

Written informed consent was obtained from each patient. The study was conducted following the ethical principles stated in the Declaration of Helsinki and approved by the University of Health Sciences Turkey, Istanbul Training and Research Hospital Ethics Committee (approval number: 2501, date: 21/08/2020).

\section{Assessments}

Data on patient demographics (age and gender), isotretinoin dose, nasal obstruction (via NOSE), and nasal dryness via a psychometric response scale (VAS; 0, none; 10, worst) and nasal Schirmer test values (right and left Schirmer values) were recorded at baseline. Nasal dryness (by VAS and nasal Schirmer test) and nasal obstruction (by NOSE) assessments were repeated at months 2 and 4 of treatment in isotretinoin groups (0.25 and $0.5 \mathrm{mg} / \mathrm{kg} / \mathrm{day})$.

\section{NOSE Questionnaire}

NOSE questionnaire, developed by Stewart et al. (19) in 2004, is a 5-item questionnaire with each item scored from 0 to 4 . For total scores, each answer is multiplied by 5 to base the scale out of a possible score of 100 (most severe nasal obstruction) for analysis as previously described, whereby higher scores demonstrate more severe nasal obstruction $(19,20)$. Adaptation and validation of the Turkish version of the NOSE questionnaire were performed by Onerci Celebi et al. (21) in 2018.

\section{Nasal Schirmer Test}

Before the procedure, patients were asked to irrigate their noses with tap water and to wait for $15 \mathrm{~min}$ in a room with $22.5^{\circ} \mathrm{C}$ temperature and $33.8 \%$ humidity to adapt to the hospital environment. Whatman no. 41 strips of filter paper, known as the Schirmer test filter paper, with $35 \mathrm{~mm}$ length and $5 \mathrm{~mm}$ width (Dr. Gerhard Mann Chem. Pharm Fabrik GmBH Berlin, Germany) were used for all subjects. The moistened area on the strip removed from each nostril was recorded as left and right (bilateral) Schirmer values (in $\mathrm{mm}$ ) as previously described $(7,9)$.

\section{Statistical Analysis}

Statistical analysis was made by using MedCalc Statistical Software version 12.7.7 (MedCalc Software bvba, Ostend, Belgium; http://www. medcalc.org; 2013). The Mann-Whitney $U$ test, Friedman test, and Wilcoxon test with Bonferroni correction were used for the analysis of non-normally distributed numerical variables. Data were expressed as mean $\pm \mathrm{SD}$, median (minimum-maximum), and percent (\%) where appropriate; $p<0.05$ was considered significant.

\section{Results}

\section{Baseline Characteristics}

The mean \pm SD of the patient age was $21.1 \pm 3.4$ (range: 16-34) years, and $64.7 \%$ of the patients were female. The daily dose of isotretinoin was $0.25 \mathrm{mg} / \mathrm{kg}$ in $35(34.3 \%)$ patients and $0.5 \mathrm{mg} / \mathrm{kg}$ in $67(65.7 \%)$ patients. Overall, 60 and 46 patients adhered to month 2 and 4 visits, respectively. The daily isotretinoin dose was $0.5 \mathrm{mg} / \mathrm{kg}$ in $39(65.0 \%)$ of 60 patients assessed at month 2 visit and 32 (69.6\%) of 46 patients assessed at month 4 visit.

\section{Study Parameters in All Patients Treated with Isotretinoin}

When compared with pretreatment values, months 2 and 4 of isotretinoin treatment were associated with a significant increase in VAS scores [median (minimum-maximum), 0 (0-7) vs 3 (0.7) and 3 $(0-9), p<0.001$ each] and a significant decrease in both left [median (minimum-maximum), 19 (9-35) vs 17 (7-30) and 15 (5-35), $\mathrm{p}<0.001$ each] and right [median (minimum-maximum), 17 (10-35) vs 15 (9-35) and 15 (4-35), $p<0.001$ each] Schirmer values. Month 4 left Schirmer values were also significantly lower than month 2 values $(p<0.05)$ (Table 1, Figure 1).

\section{Study Parameters in Isotretinoin Groups}

No significant difference was noted between isotretinoin groups in terms of pretreatment and posttreatment month 2 and 4 VAS and NOSE scores and the right and left Schirmer values (Table 2).

In the $0.25 \mathrm{mg}$ isotretinoin group, the only significant change from baseline was observed for month 2 right Schirmer values $(p<0.05)$, with no significant change from baseline in month 2 VAS, NOSE, and left Schirmer values as well as in month 4 VAS, NOSE, and bilateral Schirmer values (Table 2, Figure 1).

In the $0.5 \mathrm{mg}$ isotretinoin group, when compared with pretreatment values, month 2 and 4 therapy was associated with significantly increased VAS scores $(p<0.001$ and $p<0.01$, respectively) and 
Table 1. Study parameters in all patients treated with isotretinoin

\begin{tabular}{|c|c|c|c|c|c|}
\hline & & $\begin{array}{l}\text { Pretreatment } \\
(n=102)\end{array}$ & $\begin{array}{l}\text { Month } 2 \\
(n=60)\end{array}$ & $\begin{array}{l}\text { Month } 4 \\
(n=46)\end{array}$ & $\mathbf{p}^{1}$ \\
\hline \multirow[b]{2}{*}{ VAS score } & Mean \pm SD & $1 \pm 2$ & $3 \pm 2^{*}$ & $4 \pm 3^{*}$ & \multirow[b]{2}{*}{$<0.001$} \\
\hline & $\begin{array}{l}\text { Median } \\
\text { (min.-max.) }\end{array}$ & $0(0-7)$ & $3(0-7)$ & $3(0-9)$ & \\
\hline NOSE score & $\begin{array}{l}\text { Median } \\
\text { (min.-max.) }\end{array}$ & $0(0-40)$ & $0(0-40)$ & $5(0-35)$ & 0.705 \\
\hline \multicolumn{6}{|c|}{ Nasal Schirmer test } \\
\hline \multirow{2}{*}{$\begin{array}{l}\text { Right } \\
\text { Schirmer } \\
\text { value }\end{array}$} & Mean \pm SD & $20 \pm 6$ & $17 \pm 6^{*}$ & $16 \pm 7^{*}$ & $<0.001$ \\
\hline & $\begin{array}{l}\text { Median } \\
\text { (min.-max.) }\end{array}$ & $17(10-35)$ & $15(9-35)$ & $15(4-35)$ & - \\
\hline \multirow{2}{*}{$\begin{array}{l}\text { Left } \\
\text { Schirmer } \\
\text { value }\end{array}$} & Mean \pm SD & $20 \pm 6$ & $17 \pm 6^{*}$ & $16 \pm 7^{*,+}$ & $<0.001$ \\
\hline & $\begin{array}{l}\text { Median } \\
\text { (min.-max.) }\end{array}$ & $19(9-35)$ & $17(7-30)$ & $15(5-35)$ & - \\
\hline
\end{tabular}

VAS: Visual analog scale, NOSE: nose obstruction symptom evaluation, SD: standard deviation, min.: minimum, max.: maximum, 1 : Friedman test, ${ }^{*}: p<0.001$ compared with pretreatment values (Wilcoxon test with Bonferroni correction, $p<0.016$ ), $+: p<0.05$ compared with month 2 values (Wilcoxon test with Bonferroni correction, $p<0.016$ )

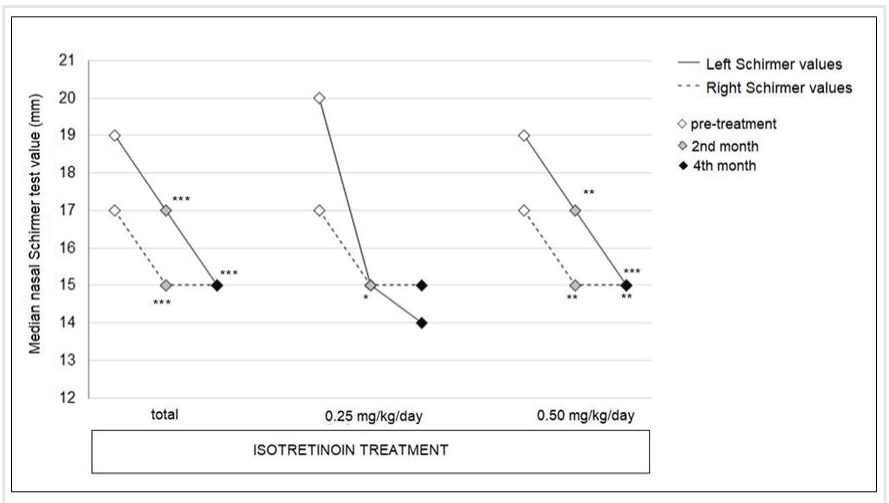

Figure 1. Nasal Schirmer test findings: right and left Schirmer values in all groups and isotretinoin groups, at baseline and months 2 and 4 of treatment

$*: p<0.05, * *: p<0.01$, and $* * *: p<0.001$; compared with pretreatment values

significantly decreased right ( $p<0.01$ for each) and left $(p<0.001$ and $p<0.01$, respectively) Schirmer values (Table 2, Figure 1).

\section{Discussion}

Our findings revealed a significant increase in nasal dryness measured via VAS scores and bilateral nasal Schirmer values in patients with isotretinoin-treated acne vulgaris, particularly when the daily dose was set at $0.5 \mathrm{mg} / \mathrm{kg}$, even within 2 months of therapy. NOSE scores reported by patients at baseline and during treatment were associated with the lack of nasal obstruction; thus, isotretinoin treatment had no significant effect on NOSE scores, regardless of the treatment dose or duration.

In the present study, the significant increase in nasal dryness scores based on both subjective (increase in VAS scores) and objective (decrease in right and left Schirmer values) measures in patients who received isotretinoin supports the consideration of mucosal dryness as the most common side effect of isotretinoin, i.e., patients on isotretinoin twice likely complained of nasal dryness compared with healthy individuals $(2,22)$.
The bilateral Schirmer values recorded at baseline in the present study were in line with the mean reference values (right, 19.8 \pm 6.9 ; left, 19.5 \pm 7.0) in the Turkish population in a previous study (7). Hence, our findings indicate the utility of the nasal Schirmer test in the objective evaluation of nasal humidity in patients with isotretinoin-treated acne vulgaris and the sensitivity of this test in discriminating the dose and treatment duration-dependent alteration in nasal dryness.

The association of $0.5 \mathrm{mg} / \mathrm{kg}$ daily dose of isotretinoin with an increase in mean VAS scores (1-3) after month 4 of treatment in our patients supports the data from previous studies indicated a significant increase in the mean VAS score of the patients from baseline (range: 0.1-2.7) to the end of isotretinoin treatment (range: 1.7-3.3) $(4,14)$.

In a study by Tasli et al. (14) conducted with 54 patients with isotretinointreated acne vulgaris, authors reported a significant increase from baseline to months 1 and 3 of treatment in mean NOSE scores (14.04, 20.11, and 19.04, respectively), VAS scores (1.59, 2.14, and 2.21, respectively), and nasal dryness/crusting severity scores $(0.47,3.57$, and 4.28 , respectively) along with a significant increase in the percentage of patients with nasal dryness from $9.5 \%$ at baseline to $43 \%$ at month 3 of isotretinoin treatment.

In a study of 40 patients with acne vulgaris, Gorpelioglu et al. (12) revealed that the mean nasal MCT significantly increased after isotretinoin treatment along with a significant correlation between drug dose and prolonged nasal clearance. The authors also noted that nasal complications caused by isotretinoin, such as signs and symptoms of dry nose and disturbed mucociliary clearance, were mild in patients on the low-dose isotretinoin regimen (12).

In a study of 101 patients with isotretinoin-treated acne vulgaris, İşlek and Yıldız (4) reported significant increase from baseline values in MCT, NOSE, and nasal dryness VAS scores and indicated the role of routine earnose-throat control in patients with isotretinoin-treated acne vulgaris to timely recognize the potential adverse effects of the drug on the nasal mucosa (4).

While mucocutaneous dryness is suggested to cause crusting, increasing the likelihood of nasal passage obstruction and complaint of nasal obstruction (14), isotretinoin had no significant effect on pretreatment NOSE scores in the current study, and nasal obstruction was not reported as a significant problem by our patients, regardless of the dose and duration of isotretinoin treatment.

In the present study, a significant increase in VAS scores and a decrease in bilateral Schirmer values from baseline to months 2 and 4 of therapy were evident only in patients receiving $0.5 \mathrm{mg} / \mathrm{kg}$ daily dose of isotretinoin. Accordingly, given the dose dependency of side effects such as dry mouth, nasal dryness, and frequent nosebleeds, which are reported more frequently in the high-dose than in low-dose groups of patients who received isotretinoin, our findings appear to support the consideration of low-dose daily isotretinoin $(0.25 \mathrm{mg} / \mathrm{kg})$ regimen for 6 months as a logical treatment approach in patients with acne vulgaris (23). Indeed, several studies have reported that when considering tolerability, efficacy, and patient satisfaction, low-dose daily treatment (0.25-0.4 mg/kg) for a total period of 6 months is most suitable for patients with moderate acne (24-27). 
Table 2. Study parameters in isotretinoin groups

\begin{tabular}{|c|c|c|c|c|c|c|c|c|}
\hline & \multicolumn{2}{|c|}{ Pretreatment $(n=102)$} & \multicolumn{2}{|l|}{ Month $2(n=60)$} & \multicolumn{2}{|c|}{ Month $4(n=46)$} & \multicolumn{2}{|l|}{$\mathbf{p}^{1}$} \\
\hline & $\begin{array}{l}0.25 \mathrm{mg} / \mathrm{kg} / \\
\text { day }(\mathrm{n}=35)\end{array}$ & $\begin{array}{l}0.50 \mathrm{mg} / \mathrm{kg} / \text { day } \\
(\mathrm{n}=67)\end{array}$ & $\begin{array}{l}0.25 \mathrm{mg} / \mathrm{kg} / \text { day } \\
(\mathrm{n}=21)\end{array}$ & $\begin{array}{l}0.50 \mathrm{mg} / \mathrm{kg} / \\
\text { day }(\mathrm{n}=39)\end{array}$ & $\begin{array}{l}0.25 \mathrm{mg} / \mathrm{kg} / \\
\text { day }(\mathrm{n}=14)\end{array}$ & $\begin{array}{l}0.50 \mathrm{mg} / \mathrm{kg} / \\
\text { day }(\mathrm{n}=32)\end{array}$ & $\begin{array}{l}0.25 \mathrm{mg} / \\
\mathrm{kg} / \text { day }\end{array}$ & $\begin{array}{l}0.50 \mathrm{mg} / \\
\mathrm{kg} / \mathrm{day}\end{array}$ \\
\hline \multicolumn{9}{|l|}{ VAS score } \\
\hline mean $\pm S D$ & $2 \pm 2$ & $1 \pm 2$ & $3 \pm 2$ & $3 \pm 2^{* * *}$ & $4 \pm 2$ & $3 \pm 3^{* * *}$ & 0.248 & $<0.001$ \\
\hline median (min.-max.) & $1(0-7)$ & $0(0-5)$ & $3(0-7)$ & $3(0-7)$ & $4(0-7)$ & $3(0-9)$ & & \\
\hline p value ${ }^{2}$ & \multicolumn{2}{|l|}{0.092} & \multicolumn{2}{|l|}{0.893} & \multicolumn{2}{|l|}{0.353} & \multicolumn{2}{|l|}{-} \\
\hline median (min.-max.) & $0(0-40)$ & $0(0-30)$ & $0(0-35)$ & $0(0-40)$ & $5(0-35)$ & $0(0-30)$ & 0.098 & 0.882 \\
\hline$p$ value ${ }^{2}$ & \multicolumn{2}{|l|}{0.228} & \multicolumn{2}{|l|}{0.547} & \multicolumn{2}{|l|}{0.053} & \multicolumn{2}{|l|}{-} \\
\hline \multicolumn{9}{|l|}{ Nasal Schirmer test } \\
\hline \multicolumn{9}{|l|}{ Right Schirmer value } \\
\hline mean $\pm S D$ & $20 \pm 6$ & $20 \pm 6$ & $17 \pm 6^{*}$ & $17 \pm 6^{* * *}$ & $17 \pm 7$ & $16 \pm 7^{* * *}$ & 0.008 & 0.001 \\
\hline mean $\pm S D$ & $21 \pm 6$ & $20 \pm 6$ & $17 \pm 6$ & $17 \pm 6^{* *}$ & $15 \pm 6$ & $17 \pm 8^{x+k x}$ & 0.059 & $<0.001$ \\
\hline median (min.-max.) & $20(12-35)$ & $19(9-35)$ & $15(10-30)$ & $17(7-30)$ & $14(10-30)$ & $15(5-35)$ & & \\
\hline$p$ value ${ }^{2}$ & \multicolumn{2}{|l|}{0.767} & \multicolumn{2}{|l|}{0.572} & \multicolumn{2}{|l|}{0.509} & \multicolumn{2}{|l|}{ - } \\
\hline
\end{tabular}

\section{Study Limitations}

First, the potential lack of generalizability appears to be an important limitation because of the relatively small sample size. Second, the short follow-up period and considerable loss to follow-up ratio also limited this study. Third, there was no data on epistaxis and mucociliary clearance, which otherwise could have extended the knowledge achieved in the present study.

\section{Conclusion}

Our findings revealed the association of isotretinoin treatment with nasal dryness but not with nasal obstruction in patients with acne vulgaris, particularly with the use of the high-dose $(0.5 \mathrm{mg} / \mathrm{kg})$ daily regimen, regardless of treatment duration. Our findings emphasize the utility of the nasal Schirmer test in the objective assessment of nasal dryness in patients who received isotretinoin treatment and the potential benefit of low-dose $(0.25 \mathrm{mg} / \mathrm{kg})$ isotretinoin regimen in reducing the risk of nasal dryness as a common etiological factor for eventual problems such as prolonged nasal clearance and epistaxis. Further larger-scale studies addressing the long-term nasal side effects of oral isotretinoin therapy are needed to develop optimal screening tools for the timely recognition, appropriate management, and follow-up of potential adverse effects of the drug on the nasal mucosa.

Ethics Committee Approval: The study was conducted following the ethical principles stated in the Declaration of Helsinki and approved by the University of Health Sciences Turkey, İstanbul Training and Research Hospital Ethics Committee (approval number: 2501, date: 21/08/2020).

Informed Consent: Written informed consent was obtained from each patient.
Peer-review: Externally peer-reviewed.

Authorship Contributions: Surgical and Medical Practices - E.Y.; Concept - E.Y., D.E., Z.C,., E.C.; Design - E.Y., D.E., Z.C.., E.C., Ö.Y.; Data Collection or Processing - E.Y., Z.Ç., E.C.; Analysis or Interpretation - E.Y., D.E., Z.Ç., Ö.Y.; Literature Search - E.Y., D.E., Z.Ç., E.C.; Writing - E.Y.

Conflict of Interest: No conflict of interest was declared by the authors.

Financial Disclosure: The authors declared that this study received no financial support.

\section{References}

1. Costa CS, Bagatin E, da Silva EM, L'ucio MM, Magin P, Riera R, et al. Oral isotretinoin for acne. Cochrane Database Syst Rev 2018; 11 : CD009435.

2. Vallerand IA, Lewinson RT, Farris MS, Sibley CD, Ramien ML, Bulloch AGM, et al. Efficacy and adverse events of oral isotretinoin for acne: a systematic review. Br J Dermatol 2018; 178: 76-85.

3. Amann PM, Merk HF, Baron JM. [Retinoids in dermatopharmacology]. Hautarzt 2014; 65: 98-105.

4. Isşlek A, Yıldız MG. Evaluation of Nasal Mucociliary Clearance, Nasal Obstruction Symptom Evaluation, and Epistaxis Severity Score in Isotretinoin Treatment. Ear Nose Throat J 2021; 100: 566-9.

5. Cengiz AB, Ozyilmaz C, Tabaru A, Kayabasi S, Ege SS, Ruzgar S, et al. Effects of oral isotretinoin on normal and wounded nasal mucosa: an experimental study. Eur Arch Otorhinolaryngol 2018; 275: 3025 31.

6. Courtiss EH, Gargan TJ, Courtiss GB. Nasal Physiology. Ann Plast Surg 1984; 13: 214-23. 
7. Server EA, Çelebi ÖA, Longur ES, Yiğit Ö. Applicability of Nasal Schirmer Test on Turkish Population and Identifying its Normal Range Values. İstanbul Med J 2018; 19: 231-4.

8. Ballenger JJ. Symposium: the nose versus the environment. Laryngoscope 1983; 93: 56-7.

9. Lindemann J, Tsakiropoulou E, Rettinger G, Gutter C, Scheithauer MO, Picavet $V$, et al. The intranasal Schirmer test: a preliminary study to quantify nasal secretion. Eur Arch Otorhinolaryngol 2014; 271: 2963-7.

10. Hwang PH, Chan JM. Retinoic acid improves ciliogenesis after surgery of the maxillary sinus in rabbits. Laryngoscope 2006; 116: 1080-5.

11. Jain R, Kim R, Waldvogel-Thurlow S, Hwang P, Cornish J, Douglas R. The effects of topical agents on paranasal sinus mucosa healing: a rabbit study. Int Forum Allergy Rhinol 2015; 5: 310-7.

12. Gorpelioglu C, Ozol D, Sarifakioglu E. Influence of isotretinoin on nasal mucociliary clearance and lung function in patients with acne vulgaris. Int J Dermatol 2010; 49: 87-90.

13. Takci Z, Simsek GG, Karabulut H, Buran Y, Karadag AS. Effect of systemic isotretinoin therapy on mucociliary clearance and nasal surface mucosa in acne patients. J Drugs Dermatol 2013; 12: e124-8.

14. Tasli H, Yurekli A, Gokgoz MC, Karakoc O. Effects of oral isotretinoin therapy on the nasal cavities. Braz J Otorhinolaryngol 2018; 86: 99104.

15. Brzezinski P, Borowska K, Chiriac A, Smigielski J. Adverse effects of isotretinoin: a large, retrospective review. Dermatol Ther 2017; 30: 2-7.

16. Çelebi ÖÖ, Server EA, Yiğit Ö, Yıldız M, Longur ES. The Impact of Septal Deviation on Intranasal Schirmer Test Values. Turk Arch Otorhinolaryngol 2018; 56: 145-8.

17. Keck T, Leiacker R, Heinrich A, Kühnemann S, Rettinger G. Humidity and temperature profile in the nasal cavity. Rhinology 2000; 38 : 167-71.
18. Keck T, Leiacker R, Heinrich A, Kühnemann S, Rettinger G. Temperature profile in the nasal cavity. Laryngoscope 2000; 110 : 651-4.

19. Stewart MG, Witsell DL, Smith TL, Weaver EM, Yueh B, Hannley MT. Development and validation of the nasal obstruction symptom evaluation (NOSE) scale. Otolaryngol Head Neck Surg 2004; 130 : 157-63.

20. Rhee JS, Sullivan CD, Frank DO, Kimbell JS, Garcia GJ. A systematic review of patient-reported nasal obstruction scores: defining normative and symptomatic ranges in surgical patients. JAMA Facial Plast Surg 2014; 16: 219-25.

21. Onerci Celebi O, Server EA, Yigit O, Longur ES. Adaptation and validation of the Turkish version of the Nasal Obstruction Symptom Evaluation Scale. Int Forum Allergy Rhinol 2018; 8: 72-6.

22. Bauer LB, Ornelas JN, Elston DM, Alikhan A. Isotretinoin: controversies, facts, and recommendations. Expert Rev Clin Pharmacol 2016; 9: 1435-42.

23. Faghihi G, Mokhtari F, Fard NM, Motamedi N, Hosseini SM. Comparing the Efficacy of Low Dose and Conventional Dose of Oral Isotretinoin in Treatment of Moderate and Severe Acne Vulgaris. J Res Pharm Pract 2017; 6: 233-8.

24. Lee JW, Yoo KH, Park KY, Han TY, Li K, Seo SJ, et al. Effectiveness of conventional, low-dose and intermittent oral isotretinoin in the treatment of acne: a randomized, controlled comparative study. $\mathrm{Br}$ J Dermatol 2011; 164: 1369-75.

25. Amichai B, Shemer A, Grunwald MH. Low-dose isotretinoin in the treatment of acne vulgaris. J Am Acad Dermatol 2006; 54: 644-6.

26. Mandekou-Lefaki I, Delli F, Teknetzis A, Euthimiadou R, Karakatsanis G. Low-dose schema of isotretinoin in acne vulgaris. Int J Clin Pharmacol Res 2003; 23: 41-6.

27. Sardana K, Garg VK, Sehgal VN, Mahajan S, Bhushan P. Efficacy of fixed low-dose isotretinoin (20 mg, alternate days) with topical clindamycin gel in moderately severe acne vulgaris. J Eur Acad Dermatol Venereol 2009; 23: 556-60. 